\title{
SUSTAINABLE FESYEN SEBAGAI UPAYA GERAKAN ZERO WASTE DALAM PEMBANGUNAN BERKELANJUTAN OLEH DESAINER
}

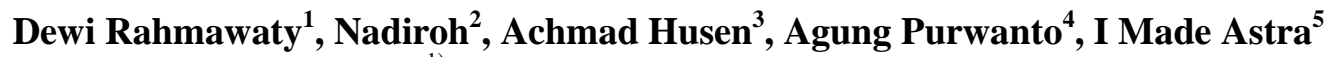 \\ ${ }^{1)}$ Sekolah Tinggi Desain Interstudi \\ ${ }^{2,3,4)}$ Universitas Negeri Jakarta \\ e-mail: dewihidayatuloh2020@gmail.com,nadiroh@unj.ac.id, ach.husen59@gmail.com, \\ agungpurwanto@unj.ac.id, imadeastra@gmail.com
}

\begin{abstract}
Abstrak
Perkembangan bisnis fesyen Indonesia semakin berkembang pesat, bahkan saat ini Indonesia sudah menjadi salah satu icon fashion muslim trend dunia, hal ini juga ditandai dengan maraknya bisnis UMKM dan UKM yang tumbuh di saat pandemi yang berfokus pada bidang fesyen. Selain penjualan produk fesyen melalui offline juga adanya market place melalui online shop juga menjadi pengaruh untuk meningkatnya penjualan dari produk fesyen. Seringnya mode berubah dalam waktu berdekatan membuat masyarakat selalu ingin update produk fesyen yang dikeluarkan dari edisi musim para desainer. Banyak masyarakat suka dengan produk fesyen yang terlihat baru untuk mengikuti perkembangan mode. Penelitian ini bertujuan untuk melihat bagaimana peran desainer mampu menerapkan sustainable fesyen sebagai gerakan zero waste dalam pembangunan berkelanjutan. Penelitian ini menggunakan studi literature review dan menggunakan analisis isi. Berdasarkan hasil literature review ditemukan bahwa para pelaku fesyen industri tak terkecuali desainer cukup berpengaruh dalam menciptakan fast fesyen yang dapat menimbulkan limbah fesyen. Implementasi sustainable fesyen dapat dilakukan dengan literasi desainer terhadap pemahaman mulai dari proses pre produksi yaitu kecakapan meminimalisir penggunaan bahan saat memotong kain, serta gerakan reuse, recycle dan reduce dari produk fesyen seta penggunaan bahan yang ramah lingkungan saat memproduksi produk fesyen. Pemerintah dan lembaga professional bidang fesyen pun didorong membuat regulasi yang mengarah kepada sustainable fesyen guna mendukung pembangunan berkelanjutan.
\end{abstract}

Kata Kunci: Sustainable Fesyen, Gerakan Zero Waste

\begin{abstract}
The development of the Indonesian fashion business is growing rapidly, even now Indonesia has become one of the world's trendy Muslim fashion icons, this is also marked by the proliferation of MSME and SME businesses that have grown during the pandemic which focuses on the fashion sector. Apart from selling fashion products via offline, the existence of a market place through an online shop is also an influence to increase sales of fashion products. Often fashion changes in the near future make people always want to update fashion products that are released from the season edition of the designers. Many people like fashion products that look new to keep up with fashion developments. This study aims to see how the role of the designer is to be able to implement sustainable fashion as a zero waste movement in sustainable development. This study used a literature review study and used content analysis. Based on the results of the literature review, it was found that the fashion industry players, including designers, are quite influential in creating fast fashion which can cause fashion waste. The implementation of sustainable fashion can be done with designer literacy towards understanding starting from the preproduction process, namely the ability to minimize the use of materials when cutting fabrics, as well as the reuse, recycle and reduce movements of fashion products and the use of environmentally friendly materials when producing fashion products. The government and professional fashion institutions are also encouraged to make regulations that lead to sustainable fashion to support sustainable development.
\end{abstract}

Keywords: Sustainable Fashion, Zero Waste Movement 


\section{PENDAHULUAN}

Dimasa pandemi saat ini banyak masyarakat yang masih enggan keluar rumah untuk mencari kebutuhan sandang, mulai dari pakaian celana atau rok serta hal lainnya yang terkait busana. Busana dapar diartikan sebagai segala sesuatu yang dipakai mulai dari ujung kepala sampai ujung kaki. Trend mode yang setiap hari update atau kekinian serta tayangan media sosial yang mempertontonkan kemodisan fesyen dari para artis atau public figure yang menstimulus masyarakat menjadi ingin selalu kekinian dalam hal berbusana. Peningkatan belanja kebutuhan sandang melalui online daripada offline di saat pandemi sekarang ini membuat bisnis bidang fesyen tidak pernah sepi. Para pelaku bisnis bidang fesyen selalu mengupdate produk fesyen dengan harga yang sangat murah, yang kalau diperhatikan kualitas dari barang yang ditawarkan sangat rendah.

Kesadaran akan kualitas bidang sandang dengan kualitas baik adalah sudah mulai digerakan oleh beberapa desainer baik nasional maupun internasional. Data di tahun 2017 menunjukkan, jangka waktu pemakaian baju sebelum dibuang, turun hingga 36 persen selama 15 tahun terakhir. Di Amerika Serikat saja, satu pakaian hanya digunakan rata-rata 40 kali sebelum dibuang.Di Jakarta dari hasil poling yang dilakukan mahasiswa Jurusan Desain Busana Sekolah Tinggi Desain Interstudi menyatakan bahwa pakaian dalam lemari hanya dipakai sekitar 2/3 dari koleksi yang ada, sehingga kegemaran membeli produk fesyen yang baru menjadi suatu masalah yang harus dicari solusinya.

Sustainable fesyen atau fesyen berkelanjutan menjadi suatu program yang sedang digalakan akhir akhir ini dari beberapa kalangan, harapannya masyarakat secara luas dapat menyadari bahwa bagaimana bisa memaknai suatu pilihan terkait fesyen.

Data dari Ellen McArthur Foundation pun menunjukkan bahwa rata-rata masyarakat di dunia membuang sekitar 12 hingga 14 ton sampah tekstil setiap detiknya. Bahan yang digunakan untuk memproduksi pakaian pun masih banyak yang menggunakan bahan buatan seperti nilon, poliester dan akrilik, yang hampir 60 persen produksi pakaian, tidak lain adalah bahan plastik yang terbuat dari minyak bumi. Hal ini tentu menjadi catatan bagi pecinta lingkungan, bagaimana bahan bahan buatan ini mendominasi bisnis fesyen saat ini.

Dari penelitian yang pernah dilakukan menunjukkan bahan-bahan seperti nilon, polyester, akrilik menghasilkan microfiber ketika dibilas dengan air yang akan berakhir di laut, dan hal ini menjadi ancaman habitat dan biota laut, dan yang paling dikhawatirkan microfiber ini juga dapat masuk ke tubuh manusia melalui olahan makanan laut yang kita konsumsi. Tentu saja, bahan-bahan sintetis ini tidak dapat terurai di tanah secara alami. Artinya, bahan-bahan ini hanya dapat hancur melalui proses pembakaran atau berakhir di tempat pembuangan sampah, di mana mereka akan tetap utuh selama ratusan tahun. Menurut World Resource Institute, emisi gas rumah kaca (GRK) yang dihasilkan dari produksi poliester juga setara dengan pengoperasian 185 pembangkit listrik tenaga batu bara setiap tahunnya.

\section{TEORETIS}

Fesyen adalah bisnis besar yang dianggap memberikan profit. Banyak yang beranggapan untuk mempertahankan eksistensi agar diakui keberadaannya dengan memperhatikan penampilan. Karena biasanya identitas sendiri serta kelompok dengan keselarasan dalam penampilan, sehingga selalu mengikuti trend mode yang selalu berkembang. Definisi fashion sangat banyak sekali, seperti dalam buku Troxxel dan Stone dalam buku Fashion Merchandising, diartikan sebagai suatu mode atau gaya yang digunakan oleh suatu kelompok tertentu dan dalam kurun masa tertentu. Dari definisi ini terlihat bahwa memang fesyen dan gaya menjadi suatu keartian.

Fesyen system termasuk didalamnya adalah organisasi, asosiasi yang terlibat dalam penciptaan arti simbolis dan dapat merubah arti dalam bentuk produk atau barang. Walaupun banyak juga yang berpendapat bahwa fesyen hanya sebatas baju atau pakaian saja, kalau kita artian fesyen dapat berarti lebih luas. Salomon dalam pendapatnya mengemukakan dalam Consumer Behaviour European Perspective Fashion yaitu proses penyebaran social (Sosial Diffusion) dimana sebuah gaya baru diadaptasi oleh beberapa konsumen.

Gaya high fesyen biasanya diperkenalkan sefta diproduksi dan dipasarkan dalam jumlah yang tidak banyak dan harga yang ditawarkan biasanya lebih mahal dari produk dengan kategori sedang. Fesyen 
dapat dikategorikan berdasarkan di kelompok fesyen leaders yang eksklusif. Sedangkan tingkatan 2 adalah produksi fesyen dalam jumlah yang banyak atau masa fesyen. Yang volumenya mengacu kepada dari daya terima gaya dan desain yang diterima oleh masyarakat.

Cycle dalam fesyen dimulai dari adanya model atau inovasi yaitu bagaimana trend mode bermula, disana biasa nya diawal dengan tawaran dari suatu model terbaru yang diperkenalkan kepada masyarakat sebagai alternative dari ragam pilihan yang ada dipasaran, tahap ke 2 yaitu perkembangan dari inovasi produk fesyen, diterima atau tidaknya sudah mulai terlihat pada fase ini, hingga masuk ke tahap ke tiga yaitu akselerasi atau percepatan, disini para pelaku penjual produk fesyen biasanya meningkatkan trik agar produknya cepat terjual. Namun tidak semua masyarakat dapat terpengaruh oleh mode fesyen yang sedang tren dipasaran. Banyak masyarakat yang berkarakter dan mengacu pada perbedaan gaya hidupnya masing masing.

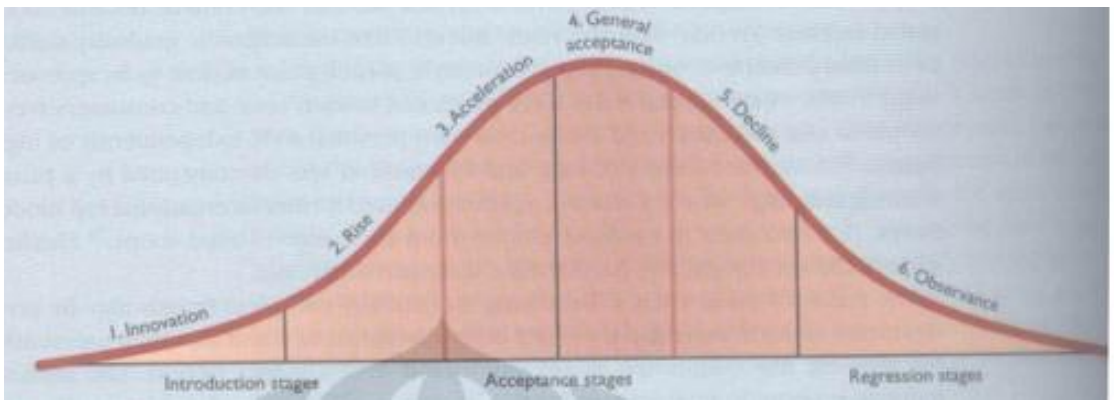

Gambar Daur Hidup Fesyen

(Sumber Salomon Michael "Customer Behaviour A European Perspective")

Untuk memahami tingkat kenutuhan seseorang akan mengacu kepada kebutuhan hirarki oleh Abraham Maslow dalam Hierarchy of Needs. Kebutuhan akan produk fesyen didasari oleh adanya kebutuhan konsumen. Implikasi dari hierarki Maslow adalah seseorang harus memuaskan kebutuhan dasarnya dahulu sebelum naik ke level kebutuhan berikutnya. Pemakaian prinsip dalam marketing sebetulnya cukup sederhana, Karena produk yang sama akan dapat memuaskan hati hanya terbatas pada kebutuhan tertentu saja. Secara psikologi pakaian dapat menutupi bagian luarnya saja. Faktor keamanan pun diperhatikan, misalya kandungan bahan agar tidak mudah terbakar ketika sedang berada di sumber api. Pada elemen lainnya fesyen harus memiliki nilai social karena akan dilihat oleh orang lain ketika dipakai, serta elemen prestise yang menandakan kelas pemakainya dan elemen terakhir yaitu aktualisasi diri yaitu sebagai ekspresi dari keseluruhan diri si pemakai.

Dalam piramida maslow mengkategorikan bagian produk fesyen yaitu pakaian adalah sebagai belongingness. Sedangkan desainer menjadi bagian dari kebutuhan prestise di pemakainya. Level ini menandakan manusia terhadap pakaian sebagai kebutuhan untuk diterima oleh orang lain atas dasar persahabatan dan cinta. Fesyen lebih berkembang menjadi symbol pemakainya agar diterima oleh lingkungannya.

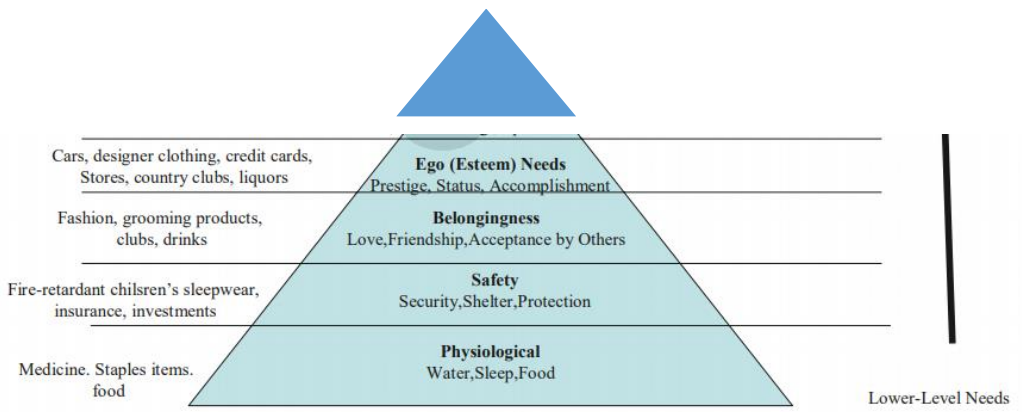

Piramida Maslow Hierarchi of Needs 


\section{METODE}

Pada tulisan sustainable feseyen digunakan dengan stui literature. Penelitian studi literatur adalah survei dan pembahasan literatur dalam bidang tertentu dari suatu arti penelitian yang telah menjelaskan gambaran singkat dari apa yang telah dipelajari, argumentasi, dan ditetapkan tentang topik penelitian tertentu, yang biasanya diorganisasikan secara kronologis atau tematis.

Terdapat beberapa hal yang menjadi penciri penelitian yang menerapkan studi literatur sebagai bentuk kajiannya, diantaranya yaitu sebagai berikut: 1) Penelitian dilakukan dengan menelaan literatur-literatur yang ada, baik yang berasal dari buku, artikel jurnal yang dihasilkan dari penelitian-penelitian sebelumnya dengan yang se-tema, maupun berbagai referensi lain yang dapat dijadikan acuan atau rujukan dalam mengkaji suatu permasalahan. 2) Variabel pada penelitian studi literatur bersifat tidak baku. Data yang telah diperoleh dianalisis secara mendalam oleh penulis. Data-data yang diperoleh tersebut dituangkan ke dalam sub bab-sub bab sehingga menjawab rumusan permasalahan yang telah ditetapkan.3) Kesimpulan yang dibuat dalam penelitian studi literatur persiapannya sama dengan penelitian lainnya, hanya saja sumber dan metode pengumpulan datanya dilakukan dengan mengambil data di pustaka, membaca, mencatat, dan mengolah bahan penelitian.

Dalam penelitian literatur kuno, analisa yang biasanya digunakan ialah pendekatan filologi untuk mengetahui informasi yang berkaitan dengan masa lampau suatu masyarakat, yang mencakup berbagai segi kehidupan yang bisa diketahui oleh masyarakat masa kini melalui peninggalan-peninggalan ada, baik peninggalan yang berupa benda maupun karya tulisan.

Studi tentang bahasa dalam sumber-sumber sejarah lisan dan tertulis; ini adalah persimpangan dari kritik tekstual, kritik sastra, sejarah, dan linguistik (dengan hubungan yang sangat kuat dengan etimologi).Filologi juga bisa diartikan sebagai studi tentang perubahan dari waktu ke waktu dalam bahasa atau rumpun bahasa tertentu. (Seseorang yang melakukan studi semacam itu dikenal sebagai seorang filolog). Dalam bukunya yang berjudul Philology: The Forgotten Origins of Modern Humanities (2014), secaraih luas, James Turner mendefinisikan istilah filologi "studi multifaset teks, bahasa, dan fenomena bahasa itu sendiri". Terdapat beberapa metode yang dapat digunakan untuk mempelajari literatur dengan baik sebagimana dirumuskan oleh bebrapa peneliti filologi, diantaranya, yaitu: Inventarisasi Literatur Langkah pertama yang harus dilakukan adalah inventarisasi atau mengumpulkan berbagai literatur yang akan diteliti beserta literatur pendukungnya. Literatur-literatur yang dibutuhkan bisa diidentifikasi dari berbagai sumber, diantaranya yaitu perpustakaan universitas atau museum yang biasanya menyimpan literatur-literatur tersebut. Daftar literatur bisa dilihat berdasarkan katalog literatur yang tersedia.

Deskripsi Literatur, Setelah literatur yang dibutuhkan terkumpul, langkah selanjutnya yaitu setelah menyusun daftar literatur yang siap digunakan, dan literatur pun telah tersedia untuk dibaca, barulah kita menguraikan atau mendeskripsikan tiap-tiap literatur yang ada secara lengkap.

Perbandingan Literatur Setelah melakukan deskripsi, langkah berikutnya dalam penelitian filologi yang membutuhkan ketekunan dan banyak waktu, adalah perbandingan literatur. Langkah yang satu ini perlu untuk dilakukan, karena sebuah cerita yang ditulis dalam dua literatur atau lebih dapat berguna untuk: Membetulkan kata-kata yang salah atau tidak terbaca, Menentukan sisilah literature, Mendapatkan literatur yang terbaik, Untuk beragam tujuan lainnya.

\section{HASIL DAN PEMBAHASAN}

Perkembangan industri fesyen yang kini menjadi salah satu penerimaan pendapatan bagi negara dengan nilai export mencapai 58,5 trilyun per tahun 2016 diberitakan oleh Global Busines Indonesia) menjadi kenyataan bahwa bisnis fesyen akan terus berkembang baik segi postif dan negatif secara bersamaan. Perhatian para pelau industri fesyen untuk menekan dampak negatif yaitu memetakan apa saja yang tidak bisa ditelorir, terutama nilai yang berlawanan dengan 17 prinsip SDGs yaitu Praktik sustainable fashion diharapkan dapat memenuhi beberapa point dalam sustainable development diantaranya adalah mengentaskan kemiskinan (1), memperbaiki kualitas kesehatan (3), kesetaraan gender (5), ketersediaan air bersih (6), pekerjaan layak dan perkembangan ekonomi (8), meningkatkan kesetaraan (10), kota dan komunitas yang berkelanjutan (11), konsumsi yang bertanggung jawab (12), mengurangi 
dampak perubahan iklim (13), menjamin kehidupan biota air dan darat $(14,15)$, dan kerjasama untuk mencapai tujuan (17).

Perkembangan industri fesyen yang terjadi di Indonesia khususnya serta dunia pada keseluruhan sudah seharusnya dapat meningkatkan kesejahteraan umat manusia, seperti yang termaktub dalam 17 pilar SDGs, selain kesejahteraan kepada manusia hal lainnya yang harus menjadi perhatian yaitu, tetap bisa memperhatikan kesejahteraan lingkungan. Sejauh mana industri fesyen dapat memperhatikan etika lingkungan.

Sustainable fesyen diharapkan mampu tetap seirama dengan perubahan trend mode yang silih berganti dari waktu ke waktu, fesyen sebagai indutri besar yang meningkatkan persentasi pertumbuhan ekonomi di Inonesia. Pelaku industri fesyen memastikan perhatian produksi baik secara masal maupun terbatas dari kegiatannya tetap harus memperhatikan kualitas dari para pekerjanya.

Namun para pelaku bisnis di industri fesyen kebanyakan belum memperhatikan secara seksama terkait lingkungan. Dari beberapa telaah yang dilakukan, Sungai Citarum di Jawa Barat merupakan sungai dengan pencemaran lingkungan terparah dikutip dari tulisan seorang Jurnalis Ecowatch, juga kejadian yang ada di Bangladesh yaitu meledaknya Rana Plaza. Sehingga kesadaran akan sustainable terus dilakukan sebagai upaya perbaikan. Pada dasarnya sustainable fesyen adalah nilai moral untuk meningkatkan nilai etika dan estetika lingkungan pada industri fesyen yang awalnya industri fesyen pada negara berkembang memiliki perputaran profit yang amat besar dengan produksi masal setiap hari nya namun tanpa memperhatikan kesejahteraan pekerjanya, serta tanpa memperhatikan bahan yang digunakan sebagai pembuat tekstilnya. Serta tanaman yang tidak ramah lingkungan dan proses pembuatan kain yang banyak menghabiskan sumber daya alam seperti air, serta penangann limbah yang harus berakhir ke laut sebagai polusi. Saat ini gerakan akan kesadaran dari sustainable fesyen sudah mulai beralih menjadi industri yang memperhatikan aspek lingkungan demi tercapainya ksejahteraan sosial bersama.

Gerakan sustainable fesyen sejalan dengan pembangunan berkelanjutan, pembangunan yang memenuhi kebutuhan dari generasi sekarang tanpa membahayakan kesanggupan generasi mendatang untuk memenuhi kebutuhan mereka sendiri. Artinya pembangunan ekonomi, selalu memanfaatkan sumber daya alam, dijalankan sedemikian rupa, sehingga generasi mendatang dapat melanjutkan pembangunan yang dijalankan sekarang. Emil Salim mendefinisikan pembangunan berkelanjutan atau suistanable development adalah suatu proses pembangunan yang mengoptimalkan manfaat dari sumber daya alam dan manusia. Pengoptimalan tersebut dengan menyerasikan sumber alam dengan manusia dalam pembangunan.

Sedangkan Ignas Kleden Pembangunan berkelanjutan sebagai jenis pembangunan yang di satu pihak mengacu pada pemanfaatan sumber-sumber alam maupun sumber daya manusia secara optimal. Di lain pihak serta pada saat yang sama memelihara keseimbangan optimal di antara berbagai tuntutan yang saling bertentangan terhadap sumber daya tersebut. Dan Sofyan Effendi Pembangunan berkelanjutan artinya suatu proses pembangunan yang memanfaatkan sumber daya, arah invesinya, orientasi pengembangan teknologi dan perubahan kelembagaan dilakukan secara harmonis dan memperhatikan potensi saat ini dan masa depan. Kemampuan generasi masa depan untuk melanjutkan pembangunan sangat bergantung dari sumber daya alam yang tersedia. Sehingga dalam melaksanakan pembangunan ekonomi saat ini tidak boleh merusak atau mengurangi kualitas lingkungan hidup.

Pembangunan yang dilakukan setiap harinya terlihat tiada henti dan tidak akan berhenti, walau saat ini pandemi Covid melanda namun pembangunan terus berjalan. Faktor pendukungan dari berlangsungnya pembangunan yang terus menerus adalah teknologi dan informasi yang selalu terkini. Pembangunan yang terus berjalan sebaiknya selalu dibarengi dengan keseimbangan dengan kebutuhan maupun ketahanan lingkungan, untuk mencapai kesejahteraan lingkungan.

Konsep pembangunan berkelanjutan yang seyogyanya membantu kesejahteraan masyarakat dapat dilihat dari aspek sebagai berikut, 1) bagaimana sumber sumber daya alam dapat dengan baik tetap bisa digunakan di masa mendatang 2) bagaimana kita dapat memanfaatkan sumber daya alam sebaik mungkin sehingga tidak ada lagi pemborosan bahkan pengrusakan lingkungan 3) Pembangunan yang dilakukan sebaiknya dapat memperbanyak sumber daya alam yang dapat diperbaharui 4) dapat mempertahankan kualitas kehidupan manusia pada masa kini maupun masa yang akan datang. 
Keseimbangan dengan lingkungan harus tetap terjaga dengan melihat juga dari aspek pemerataan, bagaimana suatu pembangunan memiliki nilai pemerataan, tidak ada kesenjangan dalam masyarakat. Metode metode yang digunakan untuk penghematan energi adalah bagaimana energi yang dapat diperbaharui secara optimal serta dapat menggunakannya secara hemat tidak boros dan baiknya dengan banyak penggunaan transportasi masal yang terintegrasi dengan baik, sehingga mengurangi polusi. Di bidang ekologi yang harus dilestarikan lingkungannya seperti penggunaan lahan campuran, memastikan tetap ada ruang terbuka hijau. Peran serta masyarakat juga sangat diperlukan pemerintah agar dapat menampung aspirasi publik. Pemerintah berperan sebagai penampung aspirasi masyarakat.

\section{SIMPULAN}

Pembangunan berkelanjutan yang tujuannya ditetapkan sejak 2015 sampai 2030, mempengaruhi juga gerakan fesyen sustainable. Berkembangnya industri fesyen pun memberikan dampak terhadap lingkungan, gerakan ini menyadarkan masyarakat terutama para pelau industri fesyen untuk peduli dengan kesejahteraan manusia, karena lingkungan yang terawat akan memberikan dampak postif bagi penghuni bumi. Kelestarian dan keterpadauan lingkungan dengan keaneka ragaman hayati pun menjadi sistem pendukung kehidupan bumi. Pada aspek ekonomi, pembangunan berkelanjutan memiliki dua hal utama adalah ekonomi makro yang menjamin untuk berjalan secara berkelanjutan dan meningkatkan efisiensi ekonomi dengan pembaruan secara nasional dan struktural.Kedua pada sektor ekonomi tercapainya sumber daya alam yang nilai ekonominya dapat diperhitungkan sebagai modal dalam kerangka akuntasi ekonomi.

Fesyen berkelanjutan dapat diukur berhasil jika stabilitas dari kemampuan penduduk terpenuhi yang didasarkan apada kebutuhan dasarnya, juga mempertahankan budaya dan dilibatkannya partisipasi lokal masyarakat dalam mengambil keputusan.

\section{SARAN}

Diharapkan produksi fesyen kedepannya dapat dilakukan dengan literasi desainer terhadap pemahaman mulai dari proses pre produksi, serta gerakan reuse, recycle dan reduce, dan penggunaan bahan yang ramah lingkungan saat memproduksi produk fesyen. Pemerintah dan lembaga professional bidang fesyen pun bisa lebih didorong membuat regulasi yang mengarah kepada sustainable fesyen guna mendukung pembangunan berkelanjutan. Kita juga perlu lebih sadar terhadap lingkungan sekitar kita karena masa depan lingkungan akan dipengaruhi oleh apa yang kita lakukan pada saat ini.

\section{UCAPAN TERIMAKASIH}

Terimakasih banyak teruntuk keluarga besar ku suami dan anak anak serta orang tua kakak yang selalu memberi dukungan. Tidak lupa pula untuk rekan rekan dosen di Sekolah Tinggi Desain Interstudi dan rekan PKLH 2020 S3 UNJ atas support yang telah diberikan selama mengerjakan jurnal ini. Teruntuk dosen dosen di pascasarjana prodi PKLH UNJ, saya juga berterimakasih banyak atas bimbingannya.

\section{DAFTAR PUSTAKA}

Amed, I, Berg \& Kappelmark S (2017). The State of Fashion 2018. The business of fashion. McKinsey \& Company

Anoraga (2010). Manajemen Bisnis, Jakarta : PT Rineka Cipta

Azheri B (2012). Corporate Social responbility : Dari voluntary menjadi mandotary. Jakarta : Rajawali Press

Brand Finance (2019). Brand Finance Global 500 2019. Retrieved Oktober 2020 from Brand Finance :htpps://brandfinance.com/knowledgecentre/reports/brad-finance-global-500-2019/

Crosno, J.L Freling TH \& Skinner SJ (2009). Does brand social power mean market might?exploring the influence of brand social power on brand evaluations. Psychology \& marketing, 26 (2)

Giovanis, A.N \& Athanasopoulou, O (2014) Gaining customer loyalty in the e-tailing marketplace : The role of e-service quality, satisfaction and e-trust. International Journal Technology Marketing. 9(3) 
Hair J.F Ringle C. M \& Sarstedt M (2011) PLS-SEM : Indeed a silver bullet. Journal of Marketing Theory and Practice, 19 (2)

Joyner Armstrong, CM Kang J \& Lang C (2018). Clothing style confidence : The development and validation of a multidimensional scale to explore product longevity : Journal of Consumer Behaviour 17 (6)

Jung S \& Jin B (2014). A theorical investigation of slow fashion : Sustainable future of the apparel industry. International journal of consumer studies 38 95)

Kim Y \& Rader (2010). What they can do versus how much they care. Journal of Communication Management. 14 (1)

Kozlowski A Searcy \& Barecki M (2015) Corporate Sustainable Reporting in The Apparel Industry : An Analysis of Indicators Dislosed, International Journal of Productivity and Performance Management (64)3

McNeill L \& Moore R (2015) Sustainable fashion Consumption and the fast fashion conundrum : Fashionable consumers and attitudes to sustanaibility in clothing choice : International Journal of Customer Studies, 39 (3)

Neuman HL Martinez LM \& M. Sustanaiblity efforts in the fast fashion industry : Consumer Perception, Trust and Purchase Ontention. Sustanaibility Accounting, Management and Policy Journal.

Nugroho, 2007. Analisis Perilaku Konsumen. Jakarta : Ghalia Indonesia

Rahman, M. S Haque M.M \& Khan A H (2012) A conceptual study on Consumers Purchase Intention of Broadband Services : Services Quality and experience economy Perspective. International Journal of Bussiness and Management, 7 (8)

Sapphira A (2019) . Memotivasi pabrik pemasok perusahaan retail pakaian untuk menjalankan bisnis berkelanjutan. Retrieved November 2020. From bisnisdanham : https://bisnisdanham.id/memotivasipabrik-pemasok-perusahaan-retail-pakaian-untuk-enjalankan-bisnis-berkalnjutan

Sekran U \& Bougie R (2016). Research Methods for Bussiness A Skil Building Approach. Unites States : John Wiley \& Sons

Shah S A (2012). The impact of Brands on Consumer Purchase Intention. Asian Journal of Bussiness Management 